\title{
DYNAMIC NOURISHMENT AND MULTI-PURPOSE ARITIFICIAL REEF AS A BEACH EROSION COUNTERMEASURE
}

\author{
Kyu-Tae Shim, CatholicKwandong University, aiqshim@gmail.com \\ Kyu-Han Kim, CatholicKwandong University, khkim@cku.ac.kr \\ Nobuhisha Kobayashi, University of Delaware, nk@udel.edu
}

\section{INTRODUCTION}

Presently, various energy power plant facilities are being constructed along the coast of the East Sea of Korea. Large-scale breakwaters are also being constructed seaward of these facilities in order to create a tranquil area for the docking facilities of ships as well as to minimize the damaging effects of tsunamis and storm surge. The construction of such large-scale coastal infrastructures has changed the wave-induced current and sediment transport patterns and caused severe erosion and deposition on the beach.

\section{FIELD SITE}

A thermal power plant was constructed in tandem with a breakwater of $1.5-\mathrm{km}$ length in $30-\mathrm{m}$ water depth on the coast of Anin along the eastern coast of Korea(Figure. 1). Diffracted waves around the breakwater caused erosion in the area of the direction of 30 to 40 degrees from the end of the breakwater. In addition, the adverse effect of the breakwater on the beach north of the Anin coast needs to be investigated. This adjacent beach was eroding and stabilized by constructing six submerged breakwaters.
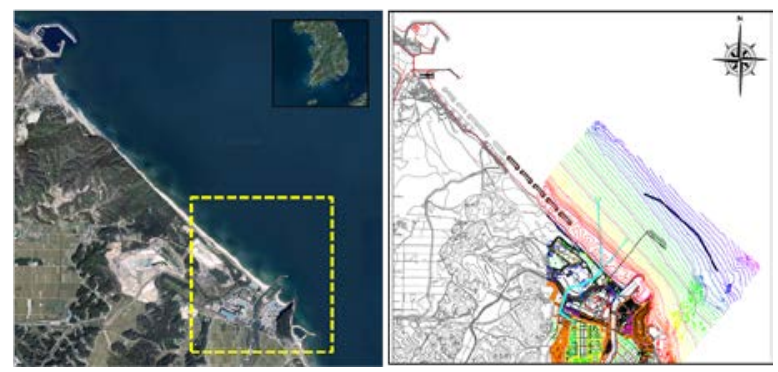

Figure 1 - Study Area in Ahnin Coast (Left), Planned Complex (Right)

\section{MITIGATION MEASURES}

Through numerical modeling and hydraulic model testing, various effects of the constructed breakwater have been confirmed, and the effectiveness of different mitigation measures has been compared. Multi-functional artificial reefs and dynamic beach nourishment have been chosen as countermeasures for minimizing the erosional effects of the breakwater on the lee side beach and the adjacent beach. Multi-functional artificial reefs(Figure. 2(L)) are submerged and do not spoil the ocean view. The shape of the reefs is optimized in triggering wave breaking and reducing wave transmission without eliminating the landward flow of water, which may be important for water quality and habitat considerations. Dynamic (adjustable) beach nourishment(Figure. 2(R)) has been designed using numerical models and physical model testing in the large wave basin of CatholicKwandong University. The experimental and numerical results will be presented at the conference.
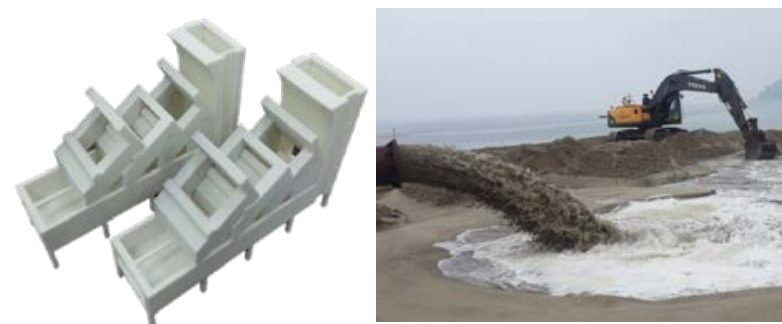

Figure. 2. - Multi-Functional Artificial Reefs(L), Dynamic Beach Nourishments (R)

\section{FIELD MONITORING}

Field observations were initiated through video monitoring prior to the breakwater construction. A drone is being used to survey the areal topography(Figure. 3 ) and measure the temporal variation of the erosion and deposition pattern on the lee side of the breakwater. The monitored results will be used to assess the accuracy of the experimental and numerical results above.

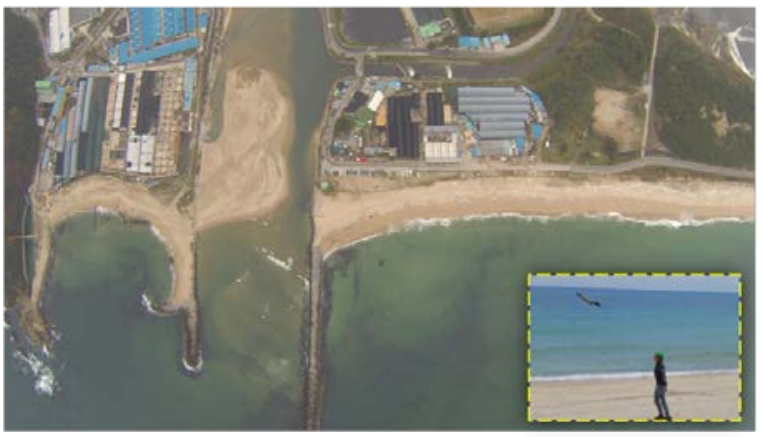

Figure. 3. - Field Investigation using Drone

\section{REFERENCES}

Ichiro Deguchi, Mamoru Arita, Kengo Tsutsui and Takuro Matsumoto (2010): Waves and Wave-Induced Current in the Decaying and Developing Process of Rip Channel. Japan Society of Civil Engineers, JSCE, 66(1), 111-115 Kim, K.-H., Yoo, H.-Y. and Kobayashi, N. (2011). Mitigation of Beach Erosion after Coastal Road Construction. Journal of Coastal Research, 27(4), 645-651.

Kobayashi, N. and Weitzner, H. (2015). Erosion of eaward Dike Slope by Wave Action. Journal of Waterway, Port, Coastal and Ocean Engineering, ASCE, 141(2), 1-7.

Takaaki Uda, Takayuki Kuchiishi, Keizo Mitsuke, Ken-ichi Kato, Susumu Taniguchi and Naohiro Akamatsu(2001), Three Dimensional Predictive Model of Beach Changes with Berm Formation Under the Action of Longshore Sand Transport, Proceedings of Civil Engineering in the Ocean, JSCE, 17, 469-474 